\title{
DIE OPENBARING VAN JOHANNES *
}

\section{DIE BOEK OPENBARING SELF - DIE STRUKTUUR}

\section{DAARVAN}

\section{Inleidende opmerking}

Die boek Openbaring is moeilik om te verstaan - daar is so baie simboliek. Die gevaar is groot dat ons alles simbolies gaan verklaar, en die boek Openbaring gaan sien as 'n simboliese voorstelling van die deurwerking van die eerste koms, dat daar eintlik maar net een koms is van die koninkryk - naamlik die eerste koms van Christus.

Die opstanding van Christus is dan dat Hy opstaan in die gelowige en in die toekomstige nuwe mensheid. Hierdie beskouing van die ewolusionisme integreer die koninkryk in die geskiedenis.

Andersyds kan die historiese en bo-historiese geskei word, en die koms van die koninkryk dan gesien word as die inslaan van die ewige in die tydelike; dat die net een kontak tussen die ewige en tydelike die persoonlike individuele belewing is; dat daar nie iets plaasvind in die geskiedenis nie en dat die verlede en toekoms van die koninkryk saamtrek in die hede.

Die koninkryk van God word losgemaak van die geskiedenis; dis maar net 'n eksistensiële belewing; alle nadruk val op die hier en nou.

By die evolusionistiese beskouing is die hede eintlik niks nie die hede is maar 'n oorgang van die verlede na die toekoms.

Die eksistensialisme lê weer alle nadruk op die hede - toekoms en verlede word saamgetrek in die hede.

Vanweë hierdie verklarings van die simboliek is dit so nodig om die lyn van die wederkoms deur die hele Nuwe Testament vas te hou.

Die beginsel dan vir die benadering van die Openbaringboek is om van dit wat duidelik is te kom tot dit wat minder duidelik is - Skrif met Skrif verklaar. 'n Mens moet die boek Openbaring benader vanuit die geskiedenis van die Openbaring.

2. Die Nieu-Testamentiese openbaring ten opsigte van die lyn van die wederkoms heg dwarsdeur die N.T. daaraan 'n historiese betekenis

i) Johannes die Doper: Christus wat sal kom om te doop met die Heilige Gees en met vuur. Heilige Gees (doop) - geskied met Pinkster. Doop met vuur - dis die voltrekking van die gerig aan die einde met die wederkoms van Christus.

* Tweede voordrag gelewer voor die G.T.V. van Pretoria deur prof. W. J. Snyman op 26 en 27 Julie 1970. Die drie voordragte is op band opgeneem en word in geredigeerde vorm in drie uitgawes van "In die Skriflig" aangebied. Die leser moet hom dus verplaas in die gehoorsaal. $-P$. W. Bingle. 
ii) Die gelykenisse waar juis die verborgenheid van die koninkryk bestaan in die tweërlei koms: die eerste koms in nederigheid; die tweede koms in heerlikheid.

iii) Die profetiese rede van Jesus, waar die wederkoms baie duidelik gestel word as 'n klaarblyklike gebeurtenis in die geskiedenis wat vir homself sal spreek en vergelyk word met die weerlig.

iv) Die Evangelie van Johannes word gewoonlik gebruik vir die vergeesteliking van die tweede koms; die oordeel vind in, gedurende die geskiedenis plaas; die ewige lewe is iets wat ons hier ontvang. Jesus sê natuurlik dat sy Vader die dode opwek en lewend maak en Hy pas dit inderdaad op die geestelike lewendmaking toe as iets wat nou gebeur. Maar dan laat Jesus onmiddellik daarop volg: „daar kom 'n uur wanneer almal in die grafte sy stem sal hoor" - Joh. $5: 25$ - en dan spreek Hy van die opstanding van die lewe en dié van die veroordeling.

Die lyn van die eerste en tweede koms loop dwarsdeur die briewe van Paulus.

Romeine 14: Ons lewe is Christus, ons sterwe is Christus, maar ons sal nog almal moet staan voor die regterstoel van Christus wat sal kom om die dode en lewende te oordeel.

1 Korinthe 15: Die Eersteling, Christus wat opgewek is; die wat aan Christus behoort by sy koms.

Kolossense 3: 4 spreek van die openbaring van Christus. Hy sal geopenbaar word en ons sal ook saam met Hom aan die einde van die dae geopenbaar word.

1 Thess. $4: 16:$,die Here self sal van die hemel neerdaal..." „Echo eimi” - bewaar die identiteit van Christus wat deur sy dood nie vernietig is nie; "kyk my hande en my voete" - sy liggaamlike identiteit (vgl. ook Lukas $24: 39$ ). Die apostel, sê die Here sal self so van die hemel neerdaal.

Wanneer die opstanding vergeestelik word, word Christus geïntegreer en sy identiteit gaan op in die nuwe mensheid. Die Bybel leer dat die identiteit van Christus nie verdwyn het nie; die behoud van identiteit van elke mens; die identiteit van 'n mens is onvernietigbaar. Die eintlike identiteit wat behou word is die individuele, die persoonlike. Dit lei na die konklusie dat volkere en nasies sal bly bestaan op die nuwe aarde; volkere en nasies word gered in hulle gelowiges, kyk Openbaring $11: 9-$ Mense uit die volke en stamme en tale en nasies beskryf die ongelowiges. (Kyk ook 2 Thess. en 1 Petrus).

Die Nuwe Testament, hou konsekwent, ook buite Openbaring, aan die wederkoms vas as 'n eindgebeurtenis. Die lyn ook in Openbaring mag nie vergeestelik word nie.

By die sesde seël kry ons 'n duidelike uitspraak van die wederkoms - die konings van die aarde, grotes en rykes wat sal roep „,berge val op ons, heuwels bedek ons" - Openb. $6: 16$.

Openb. 11 : 15 by die blaas van die sewende basuin: „die koninkryk van die wêreld het sy eiendom geword". Wat Jesus op die berg van versoeking van die hand gewys het - die koninkryk van die wêreld - word nou werklik sy eiendom, en Hy word Koning 
oor die ganse aarde.

Openb. $14: 14,20$ het duidelik te doen met die oordeel. Die doop met die vuur van Johannes die Doper kan ons deurtrek na Openb. 14. Hier weerklank die heel eerste prediking van Johannes die Doper: „,bekeer julle, want die koninkryk van God het naby gekom". Matt. 3 : 2. Presies dieselfde preek die aankondiging van die eindoordeel. "Bekeer julle" word nou "vrees God". Met ander woorde in die eindtyd sal dit nie meer 'n vraag wees van 'n verkeerde godsdiens (bekering) nie, maar die vrees van God sal weg wees, godsdiensloosheid. By die laaste dinge sal dit gaan om 'n ontkenning van die eerste dinge. (Vergelyk ook 2 Petrus) die eerste artikel van die 12 artikels, naamlik 'n ontkenning van die skepping. Dit is die kenmerk van ons tyd dat juis die skepping aangetas word.

Openb. $14: 7 \mathrm{vgl}$. met Openb. $19: 11$ v.v. Die verskyning van Christus self in heerlikheid: Hier het ons 'n duidelike punt in die boek Openbaring, 'n punt van die wederkoms van Christus wanneer Hyself sal verskyn. Die feit mag ons nie vergeestelik nie. Die wederkoms vorm by al die simboliek in die boek Openbaring 'n duidelike lyn wat deurloop.

\section{Die samestelling van die boek Openbaring}

Openbaringe is ryk aan simboliek. Dit is 'n kunswerk. Hoe meer mens jou verdiep in die boek, hoe meer bewonder jy die kunsvolle samestelling. Daar kom altyd nuwe gesigspunte na vore. Die boek is vol musiek, lofsange, van begin tot einde. Kyk na die skets wat in beeld die boek Openbaring voorstel.

Die bo-historiese lyn (vgl. boonste lyn) en die geskiedenis-lyn (vgl. onderste lyn) is die twee lyne wat ons by die Algemene Sendbriewe gevind het. Die bo-historiese moenie saamloop met die historiese lyn nie. - Dit sou die bo-historiese en die historiese uittrek; (die evolusionistiese verklaring van die boek Openbaring). Ons mag ook nie die twee lyne los sien van mekaar nie. - Ons mag nie die koninkryk van God losmaak van die geskiedenis sodat die koms van die koninkryk net gesien word as 'n eksistensialistiese belewing nie - ('n subjektiewe belewing van die ewige deur die tydelike mens wat in sy wese aangelê is op die ewige). Nee, dis twee lyne wat nooit saamval en ook nooit van mekaar geskeie staan nie. Dit omskryf die ingrype van God in die geskiedenis. Aan die einde word die teenstelling tussen die goddelike en menslike, die hemel en die aarde, weggeneem in ' $n$ harmoniese samelewing; geen integrasie, geen skeiding nie.

Voorbeeld ten opsigte van die tyd. Daar is 'n nou verband tussen die tyd en die geskiedenis. Die boonste lyn en die skets stel die ewige voor; die ewige gaan nooit in die tydelike (onderste lyn) op nie. Die tydelike word ook nooit opgeneem in die ewige nie.

Daar bestaan nie so iets dat die tyd ooit verdwyn nie. 'n Mens word nooit verhef uit die tydelike tot die bo-tydelike nie - dit sou neerkom op vergoddeliking van die mens.

Die harmoniese verbinding van die tydelike en ewige, hou vir 


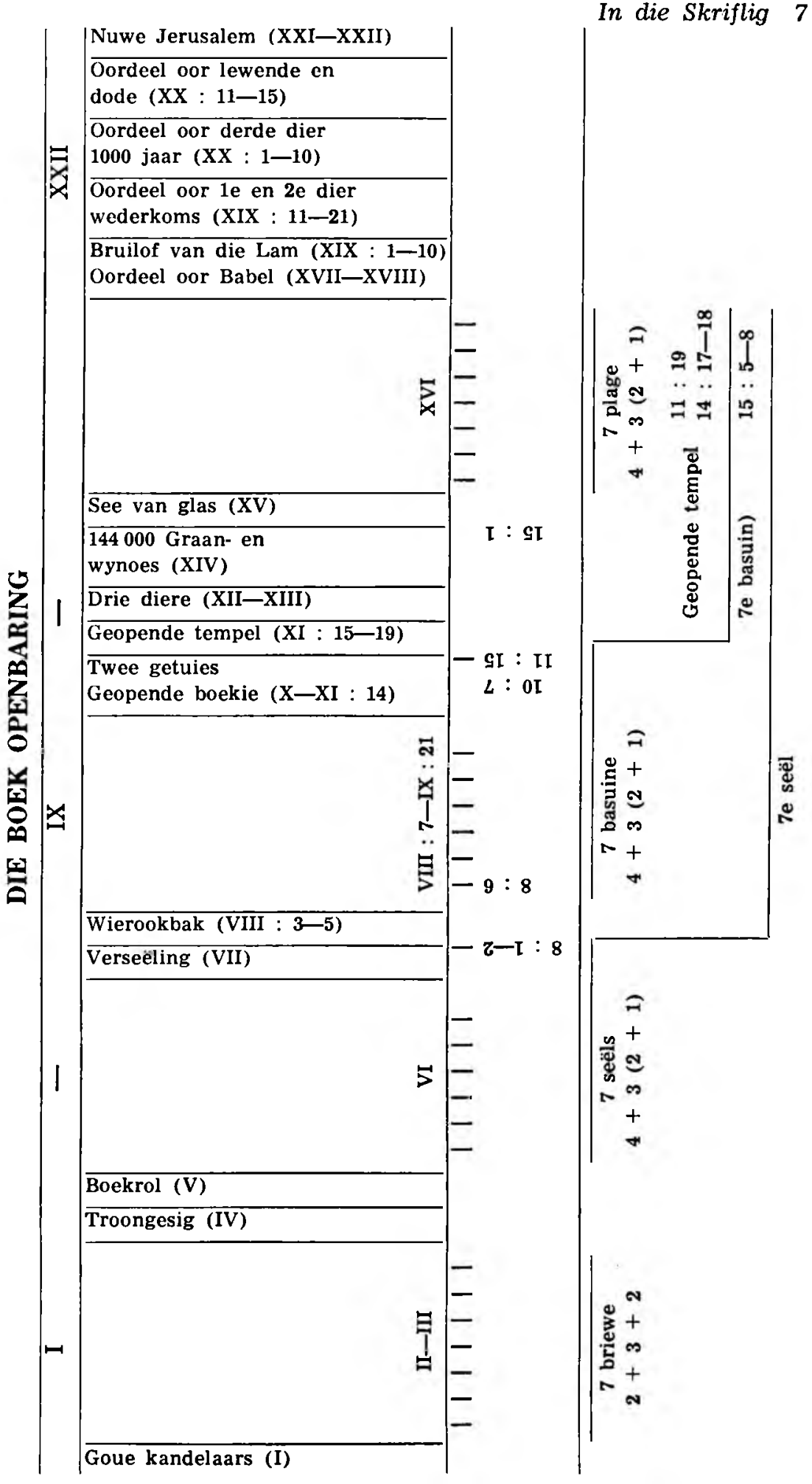


die mens in dat hy altyd sal lewe en dat hy tyd sal hê. Dit beteken nie dat tyd opgehef word nie, maar dat die verganklike en die tydelike uit die tyd weggeneem sal wees. Vir die mens en die menslike belewing beteken dit ewige tyd. - Daar is geen teenstelling tussen tyd en ewigheid nie.

Openb. 8 en 10: 6 sê daar sal geen tyd meer wees nie; die tyd van die einde is nou daar. Maar is dit nie juis 'n kenmerk van hierdie lewe dat 'n mens nie tyd het nie? Vir die mens sal die ewige lewe beteken dat hy tyd het; ' $n$ tyd wat nooit eindig nie; die ewigheid waarin die mens sal lewe. Dit is net God wat bokant tyd verhewe is; vir wie verlede, hede en toekoms alles voor Hom is. God is bokant die tyd; die mens is in die ruimte. Tyd en ruimte is geskape, en die mens is geskape in tyd en ruimte. Op die nuwe aarde sal hy ook mens bly, 'n wese wat lewe in tyd en ruimte, maar dan sal dit tyd wees sonder tydelikheid; die verganklikheid sal uit die tyd wees. Dit sal 'n ewige toekoms wees vir die mens waar die dood nie meer sal wees nie.

So kry ons die harmonie tussen ewigheid en tyd - geen sondige teenstelling nie en ook nooit vereenselwiging nie.

\section{Skematiese konstruksie van gesigte}

Die konstruksie van Openbaring bestaan uit hemelse gesigte. Johannes word in die gees opgehef na die hemelse vlak. Dan kry ons die kenmerkende van Openbaringe: a. die hemelse gesigte (vertikale lyne); b. die sewe-talle -7 briewe, 7 seëls, 7 basuine, 7 laaste plae.

Wat is die beheersende van die boek Openbaring? Dit is dat dit beheersende gesigte is. Die boek Openbaring begin met ' $n$ hemelse gesig, en dit beheers die hele geskiedenis van die kerk in die beeld van die sewe gemeentes (Openb. 2 en 3).

Die troongesig en die gesig van die boekrol beheers die sewe seëls (Openb. 4 en 5).

Die gesig van die verseëldes en van die wierookbak wat uitgestort word, beheers die gedeelte wat begin met die basuine (Openb. 7 en $8: 3-5$ ). Daar is vyf tussengesigte:

1. Hoofstuk 10-11 : 14: twee getuies; geopende boekie.

2. Hoofstuk 11 : 15-19: geopende tempel.

3. Hoofstuk 12-13: verskyning van die drie diere.

4. Hoofstuk 14: 144000; die graan- en wynoes.

5. Hoofstuk 15: see van glas.

Dan die 7 plae (Openb. 16). Dan die 5 laaste gesigte, wat eindig met die Nuwe Jerusalem (Openb. 17-22). Daar is die teenstelling - nie die verskil nie - tussen hemel en aarde, ewigheid en tyd, opgehef.

\section{Die bo-historiese visie}

Om die boek Openbaring reg te benader moet jy jou altyd stel op die boonste lyn (bo-historiese). Ons het die openbaring aangaande die geskiedenis. Die boek Openbaring laat ons diep insien in die 
geskiedenis; jy staan hoog. Jy sien die dinge wat op die aarde gebeur (seëls, basuine, plae, ens.) van bo. Die boek Openbaring hef die gelowige op bokant die geskiedenis met sy rampe en node en ellendes. Daarom hoor ons bokant die klaagtone op aarde, die jubeltone van die geloof. Openbaring gee insig in die $\sin$ van die geskiedenis; dit wat die geskiedenis beweeg.

Die Skrif roep nie net om op te kyk van onder na bo nie (Jes. 40). - As dit die geval sou wees, sou ons kon aansluit by die eksistensialisme vir wie die kwaad en die tydelike juis noodsaaklik is om te kom tot die ewige; verheerliking van die nood en kwaad om die sterretjies daarbo te sien en die ewige in jou wakker te roep. - Nee, die Bybel roep ook op om van bo na onder te kyk - Romeine 8, 1 Petrus. Daarom is hierdie hemelse gesigte beheersende gesigte.

Openbaring laat ons nie net van bo na onder kyk nie, maar laat ons ook van die einde terugkyk na die hede. Ons bekyk nie net die geskiedenis uit die verlede, hede na die toekoms nie, maar Openbaring laat ook van die toekoms terugkyk na die begin. Slegs die Bybel maak dit moontlik.

\section{Die hemelse gesigte en die gebeure op aarde}

Die sewende brief bring ons by die einde (daarom dat die lyn deurloop; dit dek die hele geskiedenis tot by die einde). Spreker staan nie op die standpunt van die kerk-historiese verklaring van die boek Openbaring nie, maar hou wel vas aan die feit dat die sewe briewe die hele geskiedenis van die kerk openbaar.

In die sewende seël is begrepe die sewe basuine. Met ander woorde die sesde seël bring ons weer aan die einde: „berge val op ons, heuwels bedek ons (Openb. $6: 16$ ). Ons word dus telkens met 'n nuwe gesigspunt deur die geskiedenis heen geneem. (Dit is nie 'n geskiedbeskrywing van die toekoms nie). So gee Openbaring altyd dieper insig in die geskiedenis. Die sesde basuin loop ook weer deur tot die einde, want die sewende basuin bevat die sewe plae.

\section{Wat sê die gesig van die kandelaar?}

Christus hou sy kerk vas! Deur alles wat mag, sal en wel gebeur, hou Christus sy kerk, die lig, vas. Let ook op hoe dikwels in die sewe briewe gesê word: „Hou vas wat julle het”.

Per slot van rekening hou Christus óns vas en dit sluit natuurlik ons verantwoordelikheid om ook vas te hou, nie uit nie. Paulus sê: "...ek jaag daarna of ek dit ook kan gryp, omdat ek ook deur Christus Jesus gegryp is" (Fil. 3 : 12). Die troos is dat die kerk nie kan ondergaan nie, want Christus hou sy kerk in stand.

\section{Die verdeling van die sewe briewe}

Die sewe briewe bestaan uit vier en drie. By die seëls en basuine is dit duidelik dat ons ' $n$ indeling het van 4 en 3 . Die 3 val uiteen in 2 en 1 (want die laaste een bevat weer die volgende reeks). 
Die opmerklike is dat by die sewe plae alles afloop, want dan is dit die einde, geen indeling nie.

Die indeling van die briewe is $2-3-2$ :

2 Efese en Smirna.

3 Pergamus, Thiatire, Sardis.

2 Filadelfia en Laodicea.

\section{Die sentrum}

Die sentrum van Openbaring is Openbaring 10 en 11 (die geopende boekie en die geopende tempel).

\section{Twee dele}

Openbaring kan in twee dele verdeel word: Voor hoofstuk 10 en hoofstuk $10-22$.

\section{Waarom die $2-3-2$ verdeling van die sewe briewe?}

Met Efese, is die groot teenstelling. „Efese, jy het jou eerste liefde verlaat" - dis die begin van alle deformasie. Uiterlik is alles nog reg, maar as jy van bo diep inkyk, soos Christus die Bruidegom kyk, sien jy dat die eerste liefde weg is. Dit is die begin van die assimilasie, die integrasie van die kerk in die wêreld.

Smirna - die groot teenstelling: vervolging van die kant van die wêreld. Jy kan alleen staande bly as jy bly by die eerste liefde, anders gaan die kandelaar verdwyn.

Die volgende drie gemeentes (Pergamus, Thiatire en Sardis) toon die ontwikkeling uit Efese plus Smirna.

Pergamus - hou nog vas aan die Naam van die Here, maar daar is ook die in die gemeente wat vashou aan die leer van Bileam (vgl. Judas), (naamlik die dwaalleraars).

Thiatire - 'n stap verder. Hulle laat al die dwaalleraars in die gemeente toe.

Sardis - uiterlik is daar nog lewe, maar innerlik dood. 'n Proses is aan die gang wat deurwerk tot by Laodicea, wanneer die tyd aangebreek het waarvan die toestand korrespondeer met dié beskryf in 2 Petrus en Judas. Sonde en genade word ,versoen"; asof die genade van God „lei" tot ongebondenheid. Dit is die tyd van die anti-chris. Maar voordat die valse kerk in die ware kerk realiseer, kry ons eers nog die beeld van Filadelfia, die getroues wat nog vashou aan die eerste liefde. Eienaardig dat die eerste afdwaling (Efese) deurwerk na Laodicea, en dat Smirna en Filadelfia getrou bly aan Christus. Dit tref dat Laodicea, die valse kerk, nog nie afgeskryf word nie, maar dat Christus aanklop en nog roep tot bekering. Dit wys ons ook op ons roeping teenoor die verste afgedwaaldes. 


\title{
Enkele aspekte in die diskussie
}

\author{
Vrae van dr. K. S. van Wyk de Vries:
}

1. As die kerk gekom het vanweë koninkryksverwerping, kom daar dan ook 'n einde aan die kerk wanneer die koninkryk sy volheid ingaan?

2. Verhouding tyd en ewigheid: Die teenstelling word opgehef maar nie die verskil nie. Daar gaan van die geskapene niks verlore nie (en tog gaan daar son en maan en sterre verlore) anders sou God verloor.

Vrae van prof. B. Spoelstra:

1. Voer die parallelisme van die twee lyne (historiese en bo-historiese) nie tot 'n dualisme wat tot deisme kan lei nie?

2. Is daar nie gevaar in die tyds- en ruimte-beskouing nie dat ons oor God ruimtelik gaan dink?

Antwoorde:

Ten opsigte van die Openbaringboek hoef mens rie verleë te voel as jy vasgevra word nie.

Tyd en ruimte: Die Bybel bring ons altyd voor 'n misterie waar dit die verhouding van God en mens, ewigheid en tyd, betref. Dit het positiewe waarde van die mens op 'n punt te bring waar hy nie meer kan verstaan nie.

Die mens het die gawe om hom te verhef bokant die sinlik waarneembare dinge. Toe Copernicus hom verhef het bokant die dinge wat hy sinlik waarneem, het hy baie probleme in die natuur opgelos (bv. die draai van die wêreldliggame).

Die mens moet hom verhef en die natuur dwing hom tot dit wat hy nie verstaan nie, dit is: die eenheid van ruimte en tyd (Einstein). Dit hoef jou nie tot ongeloof te bring nie, maar tot aanbidding. Die hele natuur verkondig God en die onbegryplikheid van God. (Ons is hier met onbegryplike dinge besig).

Beelde is gebrekkig. Die beeld van die twee lyne hou die gevaar van dualisme in. Daarom het ons gesê: die twee lyne kom tot 'n harmonie. Die teenstelling val weg tussen tyd en ewigheid. Maar harmonie is anders as identifikasie. Die mens bly 'n wese wat in tyd lewe, hy is geskape in die tyd. Die tydelikheid val uit die tyd weg. Tyd is nie tydelikheid nie. Tyd is 'n opeenvolging van momente, maar het nie noodwendig 'n einde nie.

God omvat ons met ons tyd. Daarom, volgens 'n ander beeld omvat God ons soos die buitelyn van die sirkel in die oneindigheid. Vir God is alles ewig hede. Ons bly binne die ewigheid 'n tydelike mens. Versoening van tyd en ewigheid is dat tyd vir ons ewig word.

Die sonde het die tydelikheid in tyd gebring. $\mathrm{Na}$ hierdie lewe word die mens nie alomteenwoordig nie - jy is aan 'n plek gebonde. Daar sal 'n „hier" wees en 'n „daar", 'n „nou” en 'n „dan".

Die ewigheid omvat dus die mens. Tyd word altyd, maar die goddelike ewigheid word nie. Daarom sê die Bybel: die mens is geskape om ewig te lewe en kan die mens hom nie versoen met 'n graf nie. Iemand het gesê dat die idee van die opgaan van die individu in 'n gemeenskap, is ' $n$ kompensasie van die mens om hom te versoen met sy dood - dan word hy opgeneem in ' $n$ mensheid, en dan is die mensheid 'n ewige ding. 


\section{In die Skriflig}

Daarom val alle nadruk op die bewaking van die identiteit - Jesus gee ook na die dood die heerlike boodskap van die opstanding: "dit is Ekself" (Luk. 24 : 39), Die gelowige behou sy identiteit, tot in alle ewigheid.

\section{Vraag oor mimte:}

God omvat ons ook met ons ruimte. Ons kan dit natuurkundig probeer duidelik maak. Tans word gepraat van 'n vierde dimensie. Ek kan maar net sê: God omvat ons, die hemel omvat ons aarde - vgl. die sirkel-voorstelling. Ek is met my ruimtelikheid binne die goddelike alomteenwoordigheid.

\section{Die ruimtereise:}

Sal die mens as mens so 'n punt bereik dat hy so 'n spoed ontwikkel dat hy terselfdertyd hier en daar is? Daar lê die verskil tussen tyd en ewigheid, ruimte en ewigheid. Sal die mens die spoed so vinnig kan laat ontwikkel dat hy die grens van tyd en ruimte kan oorskry en dat hy terselfdertyd nou hier en ook nou daar kan wees?

Die ruimtereise bewys dus dat die mens altyd aan tyd gebonde is, want hy sal nooit die snelheid kan ontwikkel om tegelykertyd op die aarde en op die maan te kan wees nie.

Vraag oor die kerk:

1 Petrus kom daarop neer: Christus het nooit die wêreld verwerp nie; maar $\mathrm{Hy}$ is deur die volk en die mensheid verwerp. So verteenwoordig die kerk die teenstelling wat die verkondiging van die Woord van God meebring. So gebruik God ook die verwerping, die negatiewe om die positiewe tot stand te bring. Daarom is die kerk die voortsetting van die ware mensheid, net soos hy die voortsetting is van die ware Israel. 